\title{
Transformation of Miscanthus and Sorghum cellulose during methane fermentation
}

\author{
H. Waliszewska $\cdot$ M. Zborowska $\cdot$ B. Waliszewska $\cdot$ S. Borysiak $\cdot$ \\ A. Antczak $\cdot$ W. Czekała
}

Received: 2 August 2017 / Accepted: 15 December 2017/Published online: 8 January 2018

(C) The Author(s) 2018. This article is an open access publication

\begin{abstract}
The purpose of the paper is designation of the changes in the structure of cellulose after the methane fermentation process of Miscanthus and Sorghum harvested during the growing season and afterwards. The percentage and structure of cellulose before and after fermentation were studied. Investigations into changes of the cellulose structure were conducted by the SEC, FT-IR and XRD methods. The average percentage of cellulose after the growing season for Miscanthus varieties was higher and for Sorghum varieties was lower. As a result of the fermentation, the percentage of cellulose for both investigated species harvested in two growth seasons was lower. The degree of polymerisation for the plants harvested after the growing season was lower for the
\end{abstract}

H. Waliszewska · M. Zborowska $(\bowtie) \cdot$ B. Waliszewska Institute of Chemical Wood Technology, Poznan University of Life Sciences, 60637 Poznan, Poland e-mail: mzbor@up.poznan.pl

S. Borysiak

Institute of Chemical Technology and Engineering,

Poznan University of Technology, 60965 Poznan, Poland

A. Antczak

Department of Wood Sciences and Wood Protection, Warsaw University of Life Sciences, 02787 Warsaw, Poland

W. Czekała

Institute of Biosystems Engineering, Poznan University of Life Sciences, 60637 Poznan, Poland most feedstock. As a result of the fermentation process, the degree of polymerization increased for each of the investigated feedstock. However, crystallinity of cellulose remained at the same level for Miscanthus and decreased for Sorghum. It was shown that changes were different in the cellulose structure of the compared species.

Keywords Energy crops - Biogas production . Crystallinity of cellulose $\cdot$ Polymerisation degree of cellulose

\section{Introduction}

Cellulose is the most common natural polymer in nature which is characterised by biocompatibility, biodegradability and high chemical reactivity. What is more, the most important advantage of cellulose is its availability and inexhaustibility of its source, with biomass resources effective management. Along with the lignin and hemicelluloses, it is a main component constituting $40-90 \%$ of a plant cell wall. Cellulose is a polysaccharide built with a linear chain counting from several hundred to several thousand repeating Dglucose units that are bound together covalently by (1-4) $\beta$ glycosidic linkages (Ciolacu et al. 2012). Transverse hydrogen bonds occurring between chains create a crystallinity structure, due to which cellulose is fermentable in a difficult manner (Yang et al. 2004). 
Both in lignin and in the lignin-carbohydrate complex (LCC), many ether, ester as well as covalent linkages occur, which inhibit hydrolysis reactions of biomass components and its fermentation. Therefore, the first steps before fermentation of feedstock with the higher content of cellulose and LCC should be material pretreatment in order to break bonds in cellulose and in LCC (Li et al. 2015). According to Li et al. (2011) after releasing cellulose from LCC sheath, the first step of the fermentation process is depolymerisation throughout cellulolytic bacteria, which produce cellulase. Subsequently, the cellulose disintegration products (such as cellobiose and soluble cellulodextrin of higher order) can be transformed into methane and carbon dioxide after a series of transformations (Bhadra et al. 1986; Lynd et al. 2002; Zhang and Lynd 2005; Jeihanipour et al. 2010, 2011).

One of feedstocks for a biofuel production is Miscanthus. Its energy value is 18.01-19.20 $\mathrm{MJ} \mathrm{kg}^{-1}$ d.m. (Brosse et al. 2012; Dukiewicz et al. 2014). In order to determine usefulness of that species for bioethanol production Lee and Kuan (2015) specified the content of cellulose in a variety of Miscanthus $\times$ giganteus, Miscanthus sacchariflorus and Miscanthus sinensis, and those values amounted to $41.1,38.9$ and $37.6 \%$, respectively. Research on application of Miscanthus species in biorefinery was also conducted by Tolbert et al. (2014). The authors showed that the content of cellulose in that species is approximately $37.0 \%$. Quin et al. (2012) compared four varieties of Miscanthus to recognize genetic diversity between them and their application to biofuel production. They showed that percentage of cellulose for variety of Miscanthus sacchariflorus and Miscanthus sinensis achieves 38.5 and $35.1 \%$, respectively. Brosse et al. (2012) conducted research on the chemical composition of the varieties of Miscanthus harvested twice a year in order to show the best feedstock for biorefinery purposes. They received the cellulose content ranging from 43.1 to $50.3 \%$ from plants harvested in November, whereas for the harvest in February they received the content of cellulose from 45.4 to $52.2 \%$.

Among cereals crops at the world level, Sorghum comes in the 5th position after maize, rice, wheat and barley (Popescu and Condei 2014). Its energy value is $17.75 \mathrm{MJ} \mathrm{kg}^{-1}$ d.m. of stems, similar to that of maize $-17.79 \mathrm{MJ} \mathrm{kg}^{-1}$ d.m. of stems (Kozłowski et al. 2007; Pazderu et al. 2014; Prażak 2016). Anami et al.
(2015) have investigated the content of cellulose in a variety of Sorghum for energy purposes. The authors have shown that percentage of that component is relatively low taking into account plant biomass and is $23 \%$. Stefaniak et al. (2012) have investigated changes of biomass for Sorghum and they received from 21 to $45 \%$ of cellulose. Murray et al. (2008) testing different parts of the plants have shown that the content of cellulose in stems and leaves of Sorghum changes ranging from 32.4 to $38.7 \%$ and from 31.9 to $34.3 \%$, respectively. In spite of conducting much research on the composition of Miscanthus and Sorghum, the advantages of that material in a biogas production have not been shown sufficiently. However, Mayer et al. (2014) investigating the biomethane yield of various energy crops stated that Miscanthus is a promising alternative to maize for biomethanation. According to Whittaker et al.(2016) the biogas yield from Miscanthus (Miscanthus $\times$ giganteus and Miscanthus sacchariflorus) depends on inter alia its harvest time. The significance of chemical composition in fermentation process exemplified by Miscanthus $\times$ giganteus and Sorghum bicolor was investigated by Godin et al. (2013). The research to date has not found to what extent the biomass, especially main sources of methane which are carbohydrates, ferments. Neither the loss of that component nor the changes of its structure have been investigated.

The aim of the paper was to determine whether the selected energy varieties of Miscanthus (Miscanthus $\times$ giganteus, Miscanthus sacchariflorus and Miscanthus sinensis) and Sorghum (Sorghum saccharatum and Sorghum bicolor) harvested in two different seasons (spring and autumn) vary in the range of the percentage and the structure of the main polymer component of biomass-cellulose. The second objective was to evaluate the changes of the percentage and the structure of cellulose during the methane fermentation process of the above feedstocks. These objectives were intended to clarify whether the percentage or structural differences of the cellulose of fiber plants are important during the degradation processes that it undergoes in the anaerobic digestion process. These studies will allow a detailed analysis of the extent to which cellulose undergoes fermentation and which chemical changes it undergoes. 


\section{Materials and methods}

Plant material and sampling

Three varieties of Miscanthus: Miscanthus $\times$ giganteus, Miscanthus sacchariflorus and Miscanthus sinensis and two varieties of Sorghum: Sorghum saccharatum and Sorghum bicolor were used in the investigation. Plants of species of Miscanthus came from Institute of Plant Genetics of the Polish Academy of Sciences from an experimental plot. Sorghum saccharatum came from University of Wrocław experimental plot located in Oława. Sorghum bicolor was grown in Mochełek near Bydgoszcz in experimental areas of the Kazimierz Wielki University in Bydgoszcz.

The feedstock was harvested twice a year: during and after the growing season. Finally, the research was conducted for 6 feedstocks from species of Miscanthus and 4 feedstocks from species of Sorghum.

Biomass for the chemical analysis was ground in a laboratory mill (Fritsch type 15) using a sieve with $1.0 \mathrm{~mm}$ square screens. The material was passed through brass sieves to separate the $0.5-1.0 \mathrm{~mm}$ fraction and stored at room temperature prior to use. The moisture of the feedstock used for chemical analysis ranged from 5.2 to $5.7 \%$ and 6.5 to $7.6 \%$ for Miscanthus and Sorghum, respectively. Before fermentation, plants had been cut to $100-150 \mathrm{~mm}$ pieces using scissors and had been air dried. The moisture of the feedstock before fermentation ranged from 11.9 to $13.8 \%$ for Miscanthus and 83.7 to $87.4 \%$ for Sorghum.

\section{Fermentation process}

The methane fermentation was performed according to Norm DIN 38 414-S8 (1985). Approximately $60 \mathrm{~g}$ of Miscanthus and $200 \mathrm{~g}$ of Sorghum with $1000 \mathrm{~g}$ of inoculum was used in the process conducted in the glass reactors with capacity of $2 \mathrm{~d} . \mathrm{m}^{3}$. The experiment was carried out in the set of multi-chamber biofermenter (Fig. 1). The tested materials were placed in the reactors and then flooded with inoculum. The reactors purged with nitrogen (to create anaerobic conditions) were placed in water bath with temperature of $39{ }^{\circ} \mathrm{C} \pm 1$ (mesophilic fermentation) to ensure optimal conditions for the process. Biogas produced in each separate chamber was transferred to cylindrical store-equalizing reservoirs, filled in with water with a barrier limiting gas

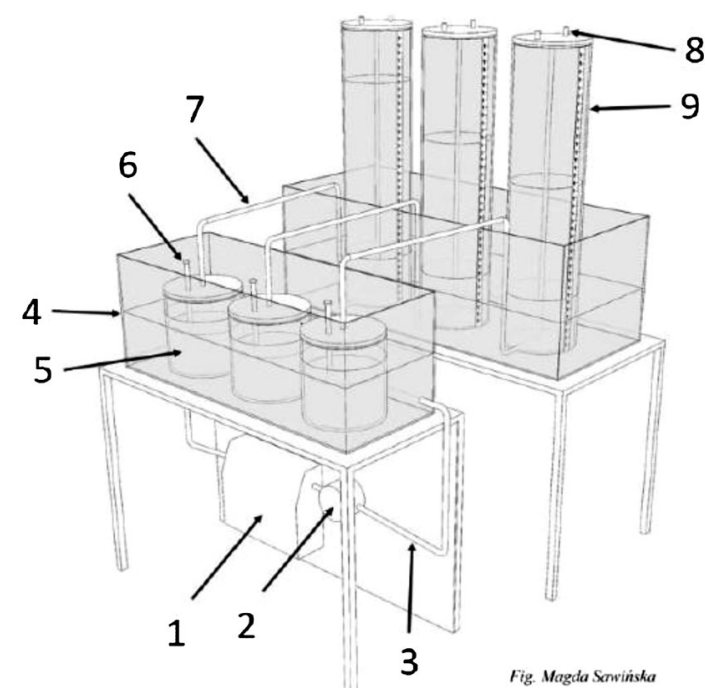

Fig. 1 Scheme of biofermentor for biogas production research (3-chamber section): 1 -water heater with temperature regulator, 2-water pump, 3-insulated conductors of calefaction liquid, 4-water coat, 5-biofermentor with charge capacity 2 d.m ${ }^{3}, 6$-sampling tubes, 7-biogas transporting tube, 8-gas sampling valve, 9- biogas volume-scale reservoir

solubility. The samples were tested in 3 replications (Cieślik et al. 2016; Lewicki et al. 2013).

Macromolecular traits of cellulose

\section{Determination of cellulose}

The cellulose percentage and its structure were investigated before and after fermentation of materials. The cellulose content was determined according to the Seifert method (Seifert 1956), using a mixture of acetylacetone, 1.4-dioxane and hydrochloric acid. Lignocellulosic material used for the determination $(1 \mathrm{~g})$ was previously extracted in ethanol. The cellulose determination was performed in water bath under condition $100{ }^{\circ} \mathrm{C}$ for $30 \mathrm{~min}$. Subsequently samples were filtered and then washed by portions of methanol, 1.4-dioxane and again methanol. The filtered cellulose was dried in a laboratory drier at $105^{\circ} \mathrm{C}$. The experimental data were analyzed using the Dell ${ }^{\mathrm{TM}}$ Statistica $^{\mathrm{TM}} 13.1$ software. For the cellulose percentage, comparisons were subjected to an analysis of variance (ANOVA) and significant differences between mean values of control and treated samples were determined using the Tukey's HSD test for $\alpha=0.05$. 


\section{Size exclusion chromatography}

The weight average polymerization degree and polydispersity index of cellulose samples were determined by SEC (Size Exclusion Chromatography) analysis. The cellulose was dissolved according to the earlier publication (Antczak et al. 2016) with some significant changes in a procedure. Detailed description of the modified procedure was as follows: in the studies cellulose samples isolated from Miscanthus and Sorghum by Seifert method were used. Prior to SEC analysis, the cellulose samples were subjected to the dissolution procedure. The dissolution started from activation of cellulose samples $(0.015 \mathrm{~g})$ in distilled water $\left(3-4 \mathrm{~cm}^{3}\right)$ during $24 \mathrm{~h}$. The next day, the samples were carried to polypropylene tubes with a narrow outlet ( 8 and $0.5 \mathrm{~mm}$-inlet and outlet internal diameters respectively), which were placed in vacuum Baker system SPE-12G. Further dissolution steps consisted of the exchange of polar substance (water) to less polar (methanol and DMAc-N,N-dimethylacetamide). In the first stage, the samples were washed with $1 \mathrm{~cm}^{3}$ of methanol, filtered and poured with the next portion of methanol and left for $1 \mathrm{~h}$. That procedure was repeated twice. After that, the samples were washed in the same manner with DMAc and after pouring the third portion of DMAc, the samples were left for $24 \mathrm{~h}$. The next day, the activated cellulose samples were filtered, transferred to a glass screw-cup test-tubes and poured with $8 \% \mathrm{LiCl}$ in DMAc $\left(4 \mathrm{~cm}^{3}\right)$. Cellulose dissolution in solvent system of $8 \% \mathrm{LiCl} /$ DMAc was realised using mixer (RM-2M, Elmi company). The total dissolution time was from 5 to 7 days. After dissolution, the part of the samples $\left(0.2 \mathrm{~cm}^{3}\right)$ was diluted to $0.5 \% \mathrm{LiCl}$ concentration with pure DMAc $\left(3 \mathrm{~cm}^{3}\right)$. Finally, the prepared samples were submitted to SEC analysis. For each sample, at least two analyses were performed.

SEC analysis of the dissolved cellulose samples was carried out using HPLC (High Performance Liquid Chromatography) system (LC-20AD, Shimadzu company), which was equipped with a differential refractive detector (RID-10A, Shimadzu), pump (LC-20AD, Shimadzu), degasser DGU-20A (Shimadzu), oven (CTO-20A, Shimadzu), controller (CBM-20A, Shimadzu) and column-cross-linked polystyrene-divinylbenzene gel (PSS GRAM 10,000, $10 \mu, 8 \times 300 \mathrm{~mm}$ ) connected with the guard column (PSS GRAM $10 \mu$ ). SEC analysis conditions were as follows: $0.5 \% \mathrm{LiCl} / \mathrm{DMAc}$ as the eluent oven temperature: $80^{\circ} \mathrm{C}$ flow rate: $2 \mathrm{~cm}^{3} / \mathrm{min}$ injection volume: $0.2 \mathrm{~cm}^{3}$.

To support the work of the chromatograph and to collect data LC Solution v.1.21 SP1 software was used. The chromatographic data were processed with software of PSS WinGPC scientific 2.74 and PSS Calibrationprogram V2.99 (Polymer Standard Service). The polystyrene standards (Polymer Laboratories) were used to calibrate the column, in which they were dissolved in $0.5 \% \mathrm{LiCl} / \mathrm{DMAc}$. Polystyrene standards molar masses ranged from 6,850,000 to $580 \mathrm{Da}$. Those polystyrene standards were used to calculate molar mass of cellulose according to MarkHouwink universal calibration:

$[\eta]=K \times M^{\alpha}$

where $\mathrm{K}$ and $\alpha$ are parameters which depend on a polymer type, solvent and temperature. For our chromatographic conditions, those parameters were as follows: for polystyrene $\mathrm{K}=17.35 \times 10^{-3} \mathrm{~cm}^{3} / \mathrm{g}$ and $\alpha=0.642$ (Timpa 1991) and for cellulose $\mathrm{K}=2.78 \times 10^{-3} \mathrm{~cm}^{3} / \mathrm{g}$ and $\alpha=0.957$ (Bikova and Treimanis 2002). Finally, on the basis of the weight average molar mass of cellulose $\left(\mathrm{M}_{\mathrm{w}}\right)$, the weight average polymerization degree was calculated:

$D P_{w}=\frac{M_{w}}{162}$

In turn, the polydispersity index of cellulose was calculated as the ratio of the weight average molar mass of cellulose to the number average molar mass:

$D P I=\frac{M_{w}}{M_{n}}$

\section{$X$-ray diffraction}

The crystallinity of cellulose was analysed by averages of wide angle X-ray scattering (WAXS) using $\mathrm{Cu}$ $\mathrm{K} \alpha$ radiation at $30 \mathrm{kV}$ and $25 \mathrm{~mA}$ anode excitation. The X-ray diffraction pattern was recorded for the angles from the range of $2 \Theta=10^{\circ}-30^{\circ}$ in the step of $0.04^{\circ} / 3 \mathrm{~s}$. The diffraction pattern showed three peaks at $2 \Theta=15^{\circ}, 17^{\circ}$ and $22.7^{\circ}$ assigned to cellulose $\mathrm{I}$. Deconvolution of peaks was performed by the method proposed by Hindeleh and Johnson (1971), improved and programmed by Rabiej (1991). After separation of $\mathrm{X}$-ray diffraction lines, the crystallinity index $\left(\mathrm{X}_{\mathrm{c}}\right)$ of 
wood after chemical treatment was calculated by comparison of areas under crystalline peaks and amorphous curve.

\section{Fourier transform infrared (FTIR) spectroscopy}

Fourier transform-infrared (FT-IR) spectra were obtained by averages of Alfa FT-IR spectrometer produced by Bruker Optics GmbH. Powder samples of cellulose $(2 \mathrm{mg}$ ) were dispersed in a matrix of $\mathrm{KBr}$ (200 mg), followed by compression to form pellets. The sample collection was obtained using 32 scans, in the range of $4000-400 \mathrm{~cm}^{-1}$, at a resolution of $4 \mathrm{~cm}^{-1}$. Three different measurements for each cellulose sample were evaluated, and the average value was considered. The energy of the hydrogen bonds $\left(\mathrm{E}_{\mathrm{H}}\right)$ for several $\mathrm{OH}$ stretching bands was calculated using Eq. (4) (Struszczyk 1986; Poletto et al. 2014):

$E_{H}=\frac{1}{k} \frac{v_{0}-v}{v_{0}}$

where $v_{0}$ is the standard frequency corresponding to free $\mathrm{OH}$ groups $\left(3650 \mathrm{~cm}^{-1}\right) ; v$ is the frequency of the bonded $\mathrm{OH}$ groups; and $\mathrm{k}$ is a constant (1/ $\mathrm{k}=2.625 \times 10^{2} \mathrm{~kJ}$ ).

The hydrogen bond distances $(\mathrm{R})$ were obtained using Eq. (5) proposed by Pimentel and Sederholm as follows (Poletto et al. 2014; Pimentel and Sederholm 1956):

$\Delta v=4430 \times(2.84-R)$

where $\Delta v=v_{0}-v ; v_{0}$ is the monomeric $\mathrm{OH}$ stretching frequency, which is taken to be $3600 \mathrm{~cm}^{-1}$; and $v$ is the stretching frequency observed in the infrared spectrum of the sample.

The IR spectra were used for the calculation of the lateral order index (LOI, A1430/A898) (Nelson and O'Connor 1964) and hydrogen bond intensity (HBI, A3340/A1336) (Nada et al. 2000).

\section{Results and discussion}

The content of cellulose in the investigated plants harvested twice a year and before and after fermentation was shown in Table 1 . The average content of cellulose for species Miscanthus during the growing season was $42.2 \%$ d.m. and after it was $45.4 \%$ d.m. Slightly higher percentage of cellulose in the varieties of Miscanthus harvested at maturity was marked by Brosse et al. (2012) as well as by Lee and Kuan (2015). It the case of species Sorghum, the plants harvested after the growing season had lower average cellulose percentage, which amounted to $39.8 \%$. The research of cellulose content in the range of energy application of Sorghum was performed by Anami et al. (2015). The results they received were significantly lower and amounted to $23 \%$. Stefaniak et al. (2012) also investigated chemical composition of Sorghum and obtained results of cellulose percentage ranging from 21 to $45 \%$. For all investigated varieties of Miscanthus and for Sorghum saccharatum the cellulose content was higher for the plants at maturity harvested after the growing season. The obtained results are consistent with opinion that the accessibility of the sugars contained in the lignocelluloses varies among plant species and their degree of lignification which is related to their maturity (Amougou et al. 2011). It was found that the cellulose content in all investigated plants after the fermentation was lower than before. Obtained differences of percentage are statistically different in the most cases, which confirms the component participation in a biogas production. The biggest loss of cellulose up to $32.7 \%$ was found in 'green' S. bicolor harvested during the growing season. This can be results from increase of sugars accessibility in younger plants (Dhugga 2007). In the case of M. sacchariflorus and M. sinensis loss of cellulose as a result of fermentation proved to be much higher for materials at maturity harvested after the growing season. However, for M. $\times$ giganteus and $\mathrm{S}$. saccharatum, loss of cellulose during biogas production was similar for feedstock harvested during and after the growing season. In those varieties a slight increase in the cellulose content during the growing season was also found and probably accessibility of sugars was also similar. The degree of polymerisation (DP) and crystallinity index (CI) of cellulose in the investigated plants harvested twice a year before and after fermentation is shown in Table 2. The average values of cellulose DP for Miscanthus variates were higher than for Sorghum variates. What is more for all investigated variates of Miscanthus DP of cellulose was higher for younger plants harvested during a growing season. In every investigated material it was found that DP of cellulose was higher after the fermentation process. That could be caused by the participation of short-chain cellulose in fermentation. 
Table 1 Percentage of cellulose in plants before and after fermentation

\begin{tabular}{|c|c|c|c|c|}
\hline Varieties & Harvest season & $\begin{array}{l}\text { Cellulose before } \\
\text { fermentation ( } \% \text { d.m.) }\end{array}$ & $\begin{array}{l}\text { Cellulose after } \\
\text { fermentation (\% d.m.) }\end{array}$ & $\begin{array}{l}\text { Loss of } \\
\text { cellulose }(\%)\end{array}$ \\
\hline \multirow[t]{2}{*}{ M. $\times$ giganteus } & During the growing season & $45.1 \mathrm{a} \pm 0.3$ & $42.2 b \pm 0.3$ & 6.4 \\
\hline & After the growing season & $46.8 \mathrm{a} \pm 0.6$ & $44.2 \mathrm{~b} \pm 0.4$ & 5.5 \\
\hline \multirow[t]{2}{*}{ M. sacchariflorus } & During the growing season & $40.3 \mathrm{a} \pm 0.4$ & $39.6 \mathrm{a} \pm 0.7$ & 1.8 \\
\hline & After the growing season & $44.8 \mathrm{a} \pm 0.2$ & $32.7 b \pm 0.1$ & 27.1 \\
\hline \multirow[t]{2}{*}{ M. sinensis } & During the growing season & $41.3 \mathrm{a} \pm 0.3$ & $40.0 \mathrm{~b} \pm 0.7$ & 3.2 \\
\hline & After the growing season & $44.6 \mathrm{a} \pm 0.1$ & $32.9 \mathrm{~b} \pm 0.7$ & 26.2 \\
\hline \multirow[t]{2}{*}{ Average of Miscanthus } & During the growing season & $42.2 \pm 0.3$ & $40.6 \pm 0.6$ & 3.9 \\
\hline & After the growing season & $45.4 \pm 0.3$ & $36.6 \pm 0.4$ & 19.4 \\
\hline \multirow[t]{2}{*}{ S. bicolor } & During the growing season & $42.6 \mathrm{a} \pm 1.8$ & $28.7 \mathrm{~b} \pm 0.5$ & 32.7 \\
\hline & After the growing season & $38.4 \mathrm{a} \pm 0.5$ & $33.0 \mathrm{~b} \pm 0.3$ & 14.0 \\
\hline \multirow[t]{2}{*}{ S. saccharatum } & During the growing season & $39.9 \mathrm{a} \pm 0.9$ & $30.2 \mathrm{~b} \pm 1.0$ & 24.4 \\
\hline & After the growing season & $41.3 \mathrm{a} \pm 2.0$ & $31.6 b \pm 1.6$ & 23.4 \\
\hline \multirow[t]{2}{*}{ Average of Sorghum } & During the growing season & $41.3 \pm 1.4$ & $29.4 \pm 0.8$ & 28.7 \\
\hline & After the growing season & $39.8 \pm 1.3$ & $32.3 \pm 1.0$ & 18.9 \\
\hline
\end{tabular}

Mean values $(n=4) \pm$ standard deviations; identical superscripts $(a, b, c \ldots)$ denote no significant difference $(p<0.05)$ between mean values in rows according to Tukey“s HSD test (ANOVA) for the investigated treatment options

Table 2 Degree of polymerisation (DP) and crystallinity index (CI) of cellulose in plants before and after fermentation

\begin{tabular}{|c|c|c|c|c|c|c|c|}
\hline Varieties & Harvest season & $\begin{array}{l}\text { DP before } \\
\text { fermentation }\end{array}$ & $\begin{array}{l}\text { DP after } \\
\text { fermentation }\end{array}$ & $\Delta(\%)$ & $\begin{array}{l}\text { CI before } \\
\text { fermentation }\end{array}$ & $\begin{array}{l}\text { CI after } \\
\text { fermentation }\end{array}$ & $\Delta(\%)$ \\
\hline \multirow[t]{2}{*}{ M. $\times$ giganteus } & During the growing season & 3086 & 3237 & 5 & 61 & 60 & -2 \\
\hline & After the growing season & 2098 & 2536 & 21 & 64 & 61 & -5 \\
\hline \multirow[t]{2}{*}{ M. sacchariflorus } & During the growing season & 2431 & 3173 & 30 & 60 & 59 & -2 \\
\hline & After the growing season & 2403 & 2723 & 13 & 58 & - & - \\
\hline \multirow[t]{2}{*}{ M. sinensis } & During the growing season & 2849 & 3200 & 12 & 63 & 61 & -3 \\
\hline & After the growing season & 2649 & 2857 & 8 & 62 & 62 & 0 \\
\hline \multirow[t]{2}{*}{ Average of Miscanthus } & During the growing season & 2789 & 3203 & 15 & 61 & 60 & -2 \\
\hline & After the growing season & 2383 & 2705 & 13 & 61 & 60 & -2 \\
\hline \multirow[t]{2}{*}{ S. bicolor } & During the growing season & 2078 & 2199 & 6 & 58 & 50 & -14 \\
\hline & After the growing season & 2172 & 2643 & 22 & 59 & 48 & -19 \\
\hline \multirow[t]{2}{*}{ S. saccharatum } & During the growing season & 2076 & 2237 & 8 & 54 & 43 & -20 \\
\hline & After the growing season & 1872 & 2370 & 27 & 55 & 41 & -25 \\
\hline \multirow[t]{2}{*}{ Average of Sorghum } & During the growing season & 2077 & 2218 & 7 & 56 & 46 & -17 \\
\hline & After the growing season & 2022 & 2507 & 24 & 57 & 44 & -22 \\
\hline
\end{tabular}

In the case of both Sorghum varieties and M. $\times$ giganteus higher increase of cellulose DP was found for the plants harvested after the growing season. In other cases e.g. M. sacchariflorus and M. sinensis higher increase after fermentation was found for young materials harvested during the growing season. As it is shown in Table 1, the average cellulose content after fermentation was lower, on the other hand, DP (Table 2) as a result of the fermentation process was higher. The actual changes were caused by higher accessibility of short-chain cellulose to carry out the fermentation process. Such dependencies were determined in both species of the investigated plants. 
Table 3 Energy of the hydrogen bonds $\left(E_{H}\right)$ and hydrogen bond distance $(R)$ for the studied cellulose obtained from the plants harvested during and after the growing season, before and after fermentation

\begin{tabular}{|c|c|c|c|c|c|}
\hline Varieties & Harvest season & $\begin{array}{l}E_{H}(k J) \text { before } \\
\text { fermentation }\end{array}$ & $\begin{array}{l}\mathrm{E}_{\mathrm{H}}(\mathrm{kJ}) \text { after } \\
\text { fermentation }\end{array}$ & $\begin{array}{l}\mathrm{R}(\AA) \text { before } \\
\text { fermentation }\end{array}$ & $\begin{array}{l}\mathrm{R}(\AA) \text { after } \\
\text { fermentation }\end{array}$ \\
\hline \multirow[t]{2}{*}{ M. $\times$ giganteus } & During the growing season & 16.757 & 17.476 & 2.799 & 2.796 \\
\hline & After the growing season & 16.685 & 18.195 & 2.799 & 2.794 \\
\hline \multirow[t]{2}{*}{ M. sacchariflorus } & During the growing season & 16.757 & 17.476 & 2.799 & 2.796 \\
\hline & After the growing season & 16.757 & 16.685 & 2.799 & 2.799 \\
\hline \multirow[t]{2}{*}{ M. sinensis } & During the growing season & 16.685 & 16.685 & 2.799 & 2.799 \\
\hline & After the growing season & 16.757 & 16.757 & 2.799 & 2.799 \\
\hline \multirow[t]{2}{*}{ Average of Miscanthus } & During the growing season & 16.733 & 17.212 & 2.799 & 2.797 \\
\hline & After the growing season & 16.733 & 17.212 & 2.799 & 2.797 \\
\hline \multirow[t]{2}{*}{ S. bicolor } & During the growing season & 16.685 & 16.397 & 2.799 & 2.800 \\
\hline & After the growing season & 16.613 & 16.253 & 2.799 & 2.800 \\
\hline \multirow[t]{2}{*}{ S. saccharatum } & During the growing season & 16.469 & 16.685 & 2.800 & 2.799 \\
\hline & After the growing season & 16.685 & 16.685 & 2.799 & 2.799 \\
\hline Average of & During the growing season & 16.577 & 16.541 & 2.799 & 2.800 \\
\hline Sorghum & After the growing season & 16.595 & 16.469 & 2.799 & 2.799 \\
\hline
\end{tabular}

Crystallinity index of cellulose of the investigated varieties changes in the range from 54 to $64 \%$, whereas a lower value below $60 \%$ was indicated for varieties of Sorghum harvested in both seasons for plant growing. Thus, taking into account that cellulose crystallinity negatively affected biomass digestion (Xu et al. 2012), the feedstock which should undergo fermentation more easily is Sorghum. In the most of investigated cases there were no differences between crystallinity of cellulose of the plants harvested during and after the growing season and this implies that the structure was shaped at the beginning of the vegetation process. The exception was M. $\times$ giganteus at maturity for which crystallinity of cellulose was $5 \%$ higher. It was found that crystallinity of cellulose was lower in Sorghum varieties after the fermentation process. Received results ranged from 41 to $50 \%$. That may indicate that cellulose disintegration during the fermentation process comes by breaking down intra- and intermolecular hydrogen bonds. Higher changes of crystallinity of cellulose achieving $25 \%$ as a result of the fermentation process were noted for $\mathrm{S}$. saccharatum.

The energy of hydrogen bonds $\left(\mathrm{E}_{\mathrm{H}}\right)$ and hydrogen bond distances $(\mathrm{R})$ for all analyses of cellulose fibres are shown in Table 3. The average value of $E_{H}$ obtained for cellulose varieties of Miscanthus harvested during and after the growing season was the same. The average energies obtained for Sorghum were slightly lower and they differed slightly from each other. After the fermentation process the average energies of hydrogen bonds increased in the case of cellulose in varieties of Miscanthus by approximately $3 \%$, while in the case of Sorghum it did not change. The higher energy of the hydrogen bonds value for Miscanthus varieties may indicate a higher number of intramolecular hydrogen bonds in cellulose in those three varieties. The higher values were associated with lower hydrogen bond distances, which may contribute to higher interactions between intramolecular cellulose chains.

The lateral order index (LOI) is correlated with the overall degree of the ordered structure in the cellulose (Poletto et al. 2014; Corgié et al. 2011; Carrilo et al. 2004). The cellulose LOI from unfermented materials ranged from 1.966 to 2.119 and after fermentation it was a bit higher and ranged from 1.974 to 2.360 (Table 4). The hydrogen bond intensity (HBI) in cellulose of the investigated plants was at the level from 1.945 to 2.690 for unfermented feedstock. The obtained results are similar to other ones reported in literature (Poletto et al. 2014). After fermentation, for Miscanthus varieties HBI was generally higher and for Sorghum lower in both harvested variants. This phenomenon confirms different transformation of 
Table 4 Infrared lateral order index and hydrogen bond intensity of the studied cellulose

\begin{tabular}{|c|c|c|c|c|c|c|c|}
\hline \multirow[t]{3}{*}{ Species } & \multirow[t]{3}{*}{ Harvest period } & \multicolumn{3}{|c|}{ IR crystallinity ratio } & \multicolumn{3}{|l|}{ A3400/A1320 } \\
\hline & & \multicolumn{3}{|l|}{ A1429/A897 } & \multirow[b]{2}{*}{$\begin{array}{l}\text { HBI before } \\
\text { fermentation }\end{array}$} & \multirow[b]{2}{*}{$\begin{array}{l}\text { HBI after } \\
\text { fermentation }\end{array}$} & \multirow[b]{2}{*}{$\Delta \mathrm{HBI}(\%)$} \\
\hline & & $\begin{array}{l}\text { LOI before } \\
\text { fermentation }\end{array}$ & $\begin{array}{l}\text { LOI after } \\
\text { fermentation }\end{array}$ & $\Delta \mathrm{LOI}(\%)$ & & & \\
\hline \multirow[t]{2}{*}{ M. $\times$ giganteus } & During vegetation & 2.064 & 2.107 & 2.083 & & & 8.749 \\
\hline & After vegetation & 2.058 & 1.974 & -4.081 & 2.283 & 2.280 & -0.131 \\
\hline \multirow[t]{2}{*}{ M. sacchariflorus } & During vegetation & 1.966 & 2.196 & 11.698 & 1.945 & 2.089 & 7.403 \\
\hline & After vegetation & 2.032 & 2.019 & -0.639 & 1.971 & 2.112 & 7.153 \\
\hline \multirow[t]{2}{*}{ M. sinensis } & During vegetation & 2.013 & 2.004 & -0.447 & 2.069 & 2.303 & 11.309 \\
\hline & After vegetation & 2.027 & 2.045 & 0.888 & 2.077 & 2.132 & 2.648 \\
\hline \multirow[t]{2}{*}{ Mean Miscanthus } & During vegetation & 2.014 & 2.102 & 4.369 & 2.252 & 2.458 & -9.147 \\
\hline & After vegetation & 2.039 & 2.013 & -1.275 & 2.110 & 2.175 & -3.080 \\
\hline \multirow[t]{2}{*}{ S. bicolor } & During vegetation & 2.018 & 2.002 & -0.792 & 2.690 & 2.528 & -6.022 \\
\hline & After vegetation & 2.055 & 2.163 & 5.255 & 2.468 & 2.224 & -9.886 \\
\hline \multirow[t]{2}{*}{ S. saccharatum } & During vegetation & 2.119 & 2.360 & 11.37 & 2.070 & 2.070 & 0 \\
\hline & After vegetation & 2.106 & 1.981 & -5.935 & 2.233 & 2.050 & 8.195 \\
\hline \multirow[t]{2}{*}{ Mean Sorghum } & During vegetation & 2.068 & 2.181 & 5.464 & 2.380 & 2.299 & -3.403 \\
\hline & After vegetation & 2.080 & 2.072 & -0.384 & 2.424 & 2.137 & 11.839 \\
\hline
\end{tabular}

cellulose during the fermentation process in the compared feedstock.

\section{Conclusions}

The results of this study imply that the investigated plants before fermentation are characterised with various chemical composition at different development stages. The showed differences concern both the percentage and the structure of cellulose. Additionally, bigger differences were detected for Miscanthus. It can be assumed that it is for Miscanthus rather than for Sorghum that the harvest time will have bigger significance for improving biogas efficiency. Higher cellulose percentage and its lower DP for Miscanthus harvested after a growing season in comparison to young plants suggests higher biogas efficiency of plants at maturity.

Under the influence of the fermentation process the cellulose contained in the investigated material undergoes significant changes. In Miscanthus varieties the average cellulose percentage after fermentation decreased more for plants harvested after the growing season. Bigger cellulose engagement in the fermentation process in the material at maturity can be connected with its higher biogas efficiency in comparison to the 'green' one. However, the highest cellulose loss after fermentation was detected for Sorghum variety harvested during a growing season. It means that it is cellulose in 'green' Sorghum that is more prone to degradation in fermentation process conditions and will give more methane. Moreover, the feedstock of this species harvested in autumn appears also more attractive for biogas production because the cellulose loss was at a high level as a result of the fermentation process, too. For Sorghum varieties the significant decrease of cellulose crystallinity after fermentation was observed. It is especially crucial due to the fact that the fermentation process is limited by the cellulose crystallinity structure. A considerable decrease of cellulose crystallinity of Sorghum indicates that it undergoes the degradation process more easily during fermentation than cellulose of Miscanthus. As a result of the fermentation process DP changed and it was higher in all cases of the investigated cellulose. It is probably related to fermentation of short-chain cellulose. Performed investigations indicated that cellulose from varieties of Miscanthus and Sorghum undergoes different transformations at the structural level and that process changes Sorghum cellulose to a greater extent. 
Acknowledgments The work was financially supported by the Ministry of Science and Higher Education Grant BIOSTRATEG2/298241/10/NCBR/2016 Intelligent systems for breeding and cultivation of wheat, maize and poplar for optimized biomass production, biofuels and modified wood.

Open Access This article is distributed under the terms of the Creative Commons Attribution 4.0 International License (http:// creativecommons.org/licenses/by/4.0/), which permits unrestricted use, distribution, and reproduction in any medium, provided you give appropriate credit to the original author(s) and the source, provide a link to the Creative Commons license, and indicate if changes were made.

\section{References}

Amougou N, Bertrand I, Machet J-M, Recous S (2011) Quality and decomposition in soil of rhizome, root and senescent leaf from Miscanthus $\times$ giganteus, as affected by harvest date and $\mathrm{N}$ fertilization. Plant Soil 338:83-97

Anami SE, Zhang L-M, Xia Y, Zhang Y-M, Liu Z-Q, Jing H-Ch (2015) Sweet sorghum ideotypes: genetic improvement of the biofuel syndrome. Food Energy Secur 4(3):159-177

Antczak A, Radomski A, Drożdżek M, Zawadzki J, Zielenkiewicz T (2016) Thermal ageing of cellulose with natural and synthetic antioxidants under various conditions. Drewno 59(196):139-152

Bhadra A, Scharer JM, Moo-Young M (1986) Anaerobic digestion of native cellulosic wastes. World J Microbiol Biotechnol 2:349-358

Bikova T, Treimanis A (2002) Problems of the MMD analysis of cellulose by SEC using DMA/LiCl: a review. Carbohydr Polym 48:23-28

Brosse N, Dufour FA, Meng X, Sun Q, Ragauskas A (2012) Miscanthus: a fast-growing crop for biofuels and chemicals production. Bioprod Biorefining, Biofuels

Carrilo F, Colom X, Suñol JJ, Saurina J (2004) Strucutral FTIR analysis and the thermal characterization of lyocell and viscose-type fibers. Eur Polym J 40:2229-2234

Cieślik M, Dach J, Lewicki A, Smurzyńska A, Janczak D, Pawlicka-Kaczorowska J, Boniecki P, Cyplik P, Czekała W, Jóźwiakowski K (2016) Methane fermentation of the maize straw silage under meso- and thermophilic conditions. Energy 115(2):1495-1502

Ciolacu D, Pitol-Filho L, Ciolacu F (2012) Studies concerning the accessibility of different allomorphic forms of cellulose. Cellulose 19:55-68

Corgié SC, Smith HM, Walker LP (2011) Enzymatic transformations of cellulose assessed by quantitative highthroughput fourier transform infrared spectroscopy (QHTFTIR). Biotechnol Bioeng 108:1509-1520

Dhugga KS (2007) Maize biomass yield and composition for biofuels. Crop Sci 47:2211-2227

Dukiewicz H, Waliszewska B, Zborowska M (2014) Higher and lower heating values of selected lignocellulose materials. Ann WULS SGGW For Wood Technol 87:60-63

Godin B, Lamaudière S, Agneessens R, Schmit T, Goffart J-P, Stilmant D, Gerin PA, Delcarte J (2013) Chemical characteristics and biofuel potential of several vegetal biomasses grown under a wide range of environmental conditions Ind. Crops Prod 48(2013):1-12

Hindeleh AM, Johnson DJ (1971) The resolution of multipeak data in fibre science. J Phys Appl Phys 1971(4):259-263

Jeihanipour A, Karimi K, Taherzadeh MJ (2010) Enhancement of ethanol and biogas production from high-crystalline cellulose by different modes of NMO pretreatment. Biotechnol Bioeng 105(3):469-476

Jeihanipour A, Niklasson C, Taherzadeh MJ (2011) Enhancement of solubilization rate of cellulose in anaerobic digestion and its drawbacks. Process Biochem 46:1509-1514

Kozłowski S, Zielewicz W, Lutyński A (2007) Określanie wartości energetycznej Sorghum saccharatum (L.) Moench, Zea mays L. i Malva verticillata L. Łąkarstwo w Polsce 10:131-140

Lee W-Ch, Kuan W-Ch (2015) Miscanthus as cellulosic biomass for bioethanol production. Biotechnol $\mathrm{J}$ 10(6):840-854

Lewicki A, Pilarski K, Janczak D, Czekała W, Rodríguez Carmona P, Cieślik CM, Witaszek K (2013) The biogas production from herbs and waste from herbal industry. J Res Appl Agric Eng 58(1):114-117

Li Y, Park SY, Zhu J (2011) Solid-state anaerobic digestion for methane production from organic waste. Renew Sustain Energy Rev 15:821-826

Li Y, Merrettig-Bruns U, Strauch S, Kabasci S, Chena H (2015) Optimization of ammonia pretreatment of wheat straw for biogas production. $\mathrm{J}$ Chem Technol Biotechnol 90:130-138

Lynd LR, Weimer PJ, van Zyl WH, Pretorius IS (2002) Microbial cellulose utilization: fundamentals and biotechnology. Microbiol Mol Biol Rev 66:506-577

Mayer F, Gerin PA, Noo A, Lemaigre S, Stilmant D, Schmit T et al (2014) Assessment of energy crops alternative to maize for biogas production in the greater region. Bioresour Technol 166:358

Murray SC, Rooney WL, Mitchell SHE, Sharma A, Klein SE, Mullet EJ, Kresovich S (2008) Genetic improvement of Sorghum as a biofuel feedstock: II. QTL for Stem and Leaf Structural Carbohydrates. Crop Sci 48(6):2180-2193

Nada AMA, Kamel S, El-Sakhawy M (2000) Thermal behavior and infrared spectroscopy of cellulose carbamates. Polym Degrad Stab 70:347-355

Nelson ML, O'Connor RT (1964) Relation of certain infrared bands to cellulose crystallinity and crystal lattice type. Part I. Spectra of types I, II, III and of amorphous cellulose. J Appl Polym Sci 8:1311-1324

Norm DIN 38 414-S8. Bestimmung des Faulverhaltens (S8) Schlamm und Sedimente (in German). Fermentation of organic materials-Characterisation of the substrate, sampling, collection of material data, fermentation tests. Berlin: Deutsches Institut für Normung; 1985. https://www. beuth.de/de/norm/din-38414- 8/1209064

Pazderů K, Hodoval J, Urban J, Pulkrábek J, Pačuta V, Adamčik J (2014) The influence of sweet sorghum crop stand arrangement on biomass and biogass production. Plant Soil Environ 60(9):433-438 
Pimentel GC, Sederholm CH (1956) Correlation of infrared stretching frequencies and hydrogen bon distances in crystals. J Chem Phys 24:639

Poletto M, Ornaghi HL, Júnior Zattera A J (2014) Native cellulose: structure, characterization and thermal properties. Materials 7:6105-6119

Popescu A, Condei R (2014) Some considerations on the prospects of Sorghum crop. Sci Pap Ser Manag Econ Eng Agric Rural Dev 14(3):295-304

Prażak R (2016) Prospects for Sorghum cultivation in Poland. Acta Agrobot 69(2):1661

Quin J, Yang Y, Jiang J, Yi Z, Xiao L, Ai X, Chen Z (2012) Comparison of lignocellulose composition in four major species of Miscanthus. Afr J Biotech 11(62):12529-12537

Rabiej S (1991) A comparison of two X-ray diffraction procedures for crystallinity determination. Eur Polym $\mathrm{J}$ 27(9):947-954

Seifert VK (1956) Über ein neues Verfahren zur Schnellbestimmung der Rein-cellulose. Papier 10:301-306

Stefaniak TR, Dahlberg JA, Bean BW, Dighe N, Wolfrum EJ, Rooney WL (2012) Variation in biomass composition components among forage, biomass, sorghum-sudangrass, and sweet sorghum types. Crop Sci 52(4):1949-1954

Struszczyk H (1986) Modification of lignins III. Reaction of lignosulfonates with chlorophosphazenes. J Macromol Sci 23:973-992
Timpa JD (1991) Application of universal calibration in gel permeation chromatography for molecular weight determinations of plant cell wall polymers; cotton fiber. Agrric Food Chem 39:270-275

Tolbert A, Akinosho H, Khunsupat R, Naskar AK, Ragauskas AJ (2014) Characterization and analysis of the molecular weight of lignin for biorefining studies. Biofuels, Bioprod Biorefining 8(6):836-856

Whittaker C, Hunt J, Misselbrook T, Shield I (2016) How well does Miscanthus ensile for use in an anaerobic digestion plant? Biomass Bioenergy 88:24-34

Xu N, Zhang W, Ren Sh, Liu F, Zhao Ch, Liao H, Xu Z, Huang J, Li Q, Tu Y, Yu B, Wang Y, Jiang J, Qin J, Peng L (2012) Hemicelluloses negatively affect lignocellulose crystallinity for high biomass digestibility under $\mathrm{NaOH}$ and $\mathrm{H} 2 \mathrm{SO} 4$ pretreatments in Miscanthus. Biotechnol Biofuels 5:58

Yang Y, Tsukahara K, Yagishita T, Sawayama S (2004) Performance of a fixed-bed reactor packed with carbon felt during anaerobic digestion of cellulose. Biores Technol 94:197-201

Zhang Y-HP, Lynd LR (2005) Cellulose utilization by Clostridium thermocellum: bioenergetics and hydrolysis product assimilation. Proc Natl Acad Sci USA 102:7321-7325 